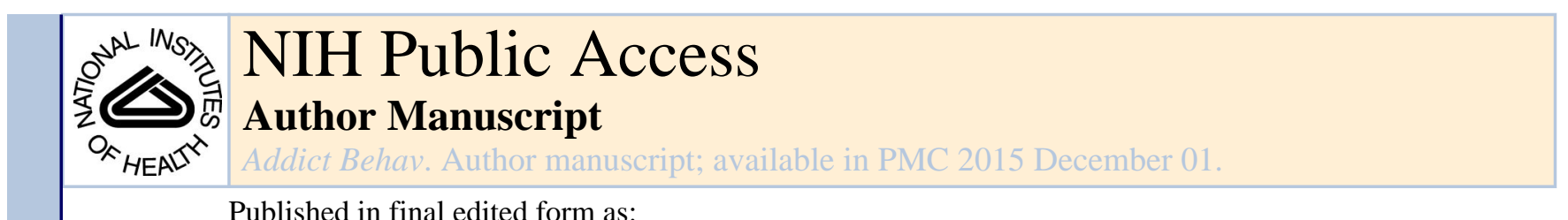

Published in final edited form as:

Addict Behav. 2014 December ; 39(12): 1804-1810. doi:10.1016/j.addbeh.2014.07.014.

\title{
The Interactive Effect of Neighborhood Peer Cigarette Use and 5HTTLPR Genotype on Individual Cigarette Use
}

\author{
Jonathan Daw ${ }^{\mathrm{a},{ }^{*}}$, Jason D. Boardman ${ }^{\mathrm{b}}$, Rachel Peterson ${ }^{\mathrm{c}}$, Andrew Smolen ${ }^{\mathrm{d}}$, Brett C. \\ Haberstick $^{d}$, Marissa A. Ehringer ${ }^{e}$, Susan T. Ennett ${ }^{f}$, and Vangie A. Foshee ${ }^{f}$ \\ aDepartment of Sociology, University of Alabama-Birmingham \\ bDepartment of Sociology, Institute of Behavioral Science, and Institute for Behavioral Genetics, \\ University of Colorado-Boulder \\ 'Department of Sociology and Institute of Behavioral Science, University of Colorado-Boulder \\ dInstitute of Behavioral Genetics, University of Colorado-Boulder \\ eDepartment of Integrative Physiology and Institute for Behavioral Genetics, University of \\ Colorado-Boulder \\ fDepartment of Health Behavior, Gillings School of Global Public Health, University of North \\ Carolina-Chapel Hill
}

\section{Abstract}

Previous cross-sectional research has shown that adolescents' cigarette use is interactively associated with that of their school peers and their 5HTTLPR genotype, such that the cigarette use of persons with more copies of the $5 H T T L P R^{*} S$ ' allele is more dependent on school peers' cigarette use behaviors than their counterparts. This analysis seeks to extend this novel finding by examining whether the same conclusion can be reached when substituting neighborhood peers for school peers and examining the timing of the initiation of any and regular smoking in adolescence. A similar conclusion is reached using an independent sample with longitudinal measures of cigarette use among $6^{\text {th }}$ through $8^{\text {th }}$ graders clustered in 82 neighborhoods, of whom 1,098 contributed genetic data. The proportion of respondents who had ever smoked cigarettes by the first wave was calculated for each Census block group in the study. 5HTTLPR genotype was assayed using the method of Whisman and colleagues (2011). The timing of any or regular smoking initiation and over four years were modeled as dependent variables using Cox

\footnotetext{
() 2014 Elsevier Ltd. All rights reserved.

"Corresponding author. jddaw @uab.edu, Address: Department of Sociology, 460 Heritage Hall Building, 1401 University Boulevard, Birmingham, AL 35294-1152.

Publisher's Disclaimer: This is a PDF file of an unedited manuscript that has been accepted for publication. As a service to our customers we are providing this early version of the manuscript. The manuscript will undergo copyediting, typesetting, and review of the resulting proof before it is published in its final citable form. Please note that during the production process errors may be discovered which could affect the content, and all legal disclaimers that apply to the journal pertain.

Disclosure

Conflict of Interest: The authors have no conflicts of interest to disclose.

Contributors: Daw, Boardman, Peterson, Smolen, Haberstick, Ehringer, Ennett, and Foshee contributed to writing the manuscript. Ennett and Foshee designed and collected the survey and genetic data. Smolen and Haberstick genotyped the genetic data. Daw and Boardman designed the statistical analysis. All authors have contributed to and approved the final manuscript.
} 
proportional hazards models. The interaction of neighborhood peer smoking behavior in the first wave and $5 H T T L P R$ genotype statistically significantly predicted any smoking initiation (hazard ratio: 3.532; $\mathrm{p}$-value $=0.002$ ) and regular smoking initiation (hazard ratio: 5.686; $\mathrm{p}$-value $=0.000$ ), net of controls for sex, race/ethnicity, grade in the first wave of data, and parental educational attainment. These findings reach the same conclusions as previous cross-sectional research. The findings for any smoking initiation are consistent with the diathesis-stress model of geneenvironment interaction; the findings for regular smoking initiation are consistent with the differential susceptibility model.

\section{INTRODUCTION}

The determinants of cigarette smoking and addiction, especially in adolescence, rightfully garner significant research attention. Tobacco use is responsible for more than 6 million deaths per year (WHO, 2012) worldwide and is associated with significant morbidity and costs to the health system. Smoking in adolescence is of particular concern because nearly $90 \%$ of smokers initiate cigarette use before the age of 18 (DHHS, 2012), and those who initiate cigarette smoking in adolescence are significantly more likely to become addicted and to smoke decades later (Breslau, Fenn, \& Peterson, 1993). Accordingly, research which enhances scientific knowledge of the determinants of adolescent tobacco use initiation is crucial to the advancement of public health.

Decades of extensive research have collectively established that social environments and genetic factors are associated with the odds of cigarette smoking initiation. Social research on this topic has focused on the role of peer behaviors. For instance, the smoking behaviors of close and extended friends is associated with one's own cigarette smoking (Alexander, Piazza, Mekos, \& Valente, 2001), as are adolescents' perceptions of peer smoking behaviors (Chassin, Presson, Sherman, Corty, \& Olshavsky, 1984) and the school and neighborhood smoking rates (Eitle \& Eitle, 2004). Similarly, neighborhood and area groupings show evidence of significant clustering of smoking behavior (Chahine, Subramanian, \& Levy, 2011; Duncan, Jones, \& Moon, 1999) and smoking initiation in adolescence (Frohlich, Potvin, Gauvin, \& Chabot, 2002). Thus, the smoking behaviors of adolescents are linked through common affiliation in a social institutions (schools and neighborhoods) as well as voluntary associations (friendships).

In parallel, a great deal of research has investigated the genetic determinants of smoking behavior and dependence. Genetic variation may be associated with smoking behavior through psychological dispositions toward risk behaviors as well as differences in the physiological consequences of nicotine (Ehringer, et al., 2010; Pedneault, et al., 2014; Saccone, et al., 2009). In the former category, one key research literature has investigated the association of the $5 H T T L P R$ polymorphism and cigarette smoking behavior. This association is plausible because variants in $5 H T T L P R$ are associated with differential serotonin uptake, which is a key neurotransmitter in mood regulation. Although a number of studies have demonstrated an association between 5HTTLPR variants and smoking behavior (Gerra, et al., 2005; Ishikawa, et al., 1999; Kremer, et al., 2005), others have obtained negative findings (Trummer, et al., 2006). 
However, many of these studies have been conducted on small samples that include limited ranges of environmental variation, suggesting the gene-environment interactions could potentially explain this inconsistency. Obviously, not all adolescents in high-smoking neighborhoods initiate smoking themselves, which suggests that certain individuals are particularly sensitive to the social influences of their immediate environments (e.g., Cicchetti, 2010). Following the publication of two influential papers (Caspi, et al., 2002; Caspi, et al., 2003), it seemed likely that particular genotypes could help to explain differential levels of susceptibility to environmental influence (Belsky \& Pluess, 2009). For instance, Boardman and colleagues (Boardman, Saint Onge, Haberstick, Timberlake, \& Hewitt, 2008) used twin behavioral genetic models to show that the variance explained by genetic factors in regular cigarette use is significantly higher for adolescents who attend schools in which more popular students also smoke more on average. Daw and colleagues (Daw, et al., 2013) built upon this work by demonstrating that a specific polymorphism in the 5HTTLPR gene (the short allele) may help account for sensitivity to peer behaviors. They predicted that those with more alleles linked to sensitivity will lead the healthiest lifestyle in the most healthy environments but also lead the most unhealthy lifestyles in the least healthy social environments (Simons, et al., 2011). This was shown to be the case with school peer smoking behavior, 5HTTLPR, and individual smoking behavior. This is known as the differential susceptibility hypothesis (Belsky \& Pluess, 2009; Caspi, et al., 2002; Conley, Rauscher, \& Siegal, 2013; Ellis, Boyce, Belsky, Bakermans-Kranenburg, \& van Ijzendoorn, 2011; Monroe \& Simons, 1991), which is usually contrasted with the diathesisstress hypothesis. Both expect more genetically susceptible individuals to show the most adverse response in the most unhealthy environments, but they differ on the predicted genetic association within the healthiest environment: the diathesis-stress model predicts equivalent outcomes by genotype in these circumstances, whereas the differential susceptibility model expects that the environmentally sensitive persons will lead the healthiest lifestyles (Belsky \& Pluess, 2009). The results from the Daw and colleagues study (Daw, et al., 2013) are consistent with the latter perspective.

However, modeling time-to-event outcomes such as smoking initiation requires some reconceptualization of these competing hypotheses, which are illustrated graphically in Figures $1 \mathrm{a}$ and $1 \mathrm{~b}$. These describe the hypothetical hazard curves for adolescents with different genotypes from different types of neighborhoods, assuming no change in baseline hazards over time for illustrative purposes. The dark lines describe those with the sensitive genotype (5HTTLPR*S'/S') and the dashed lines are for those from neighborhoods with high levels of smoking. In both the diathesis-stress (1a) and differential susceptibility (1b) models, the risk is the highest for the dashed, bold lines representing $S^{\prime} / S^{\prime}$ persons in highsmoking contexts. The difference between these models is that the solid dark line ( $\mathrm{S}^{\prime} / \mathrm{S}^{\prime}$ persons in low smoking schools) is not distinguishable from the others in the diathesis-stress model but stands out as the lowest risk of smoking initiation in the differential susceptibility model.

This paper builds on the analysis of Daw and colleagues (2013) in three key ways. First, we employ a different dataset studying youths at earlier ages $\left(6^{\text {th }}\right.$ to $8^{\text {th }}$ grade) in order to determine whether similar patterns are observed. Second, we employ longitudinal data so 
that we can analyze the role of GxEs with peer behaviors in the determination of smoking initiation rather than level alone. Third, we extend this hypothesis to apply to a different peer group - residents of the same neighborhood. Because our analysis and one key independent variable differs from that in the Daw and colleagues (2013) paper, this paper is not a replication according to strict criteria. However, results consistent with the findings of this previous paper would buttress scientific confidence in the claim that the association of peer smoking with individual smoking is mediated by the 5HTTLPR gene.

\section{METHODS}

\section{Data}

Data for this study were drawn from the Genes in Context Study. For that study, biospecimens were collected (via a self-administered saliva sample using an Oragene collection kit or a blood spot using a lancet) for genotyping from the young adults (ages 1925) who participated as adolescents in a seven-wave longitudinal study examining contextual influences on adolescent health risk behaviors. The longitudinal study included a survey of middle school children followed over seven waves (every six months for the first 6 waves, and with a one-year interval between the $6^{\text {th }}$ and $7^{\text {th }}$ ), for four years. The longitudinal study was conducted in two county-wide school systems in the Southeast US. Of the 3,835 participants of the longitudinal study, 1,519 (40\%) provided a biospecimen for genotyping.

\section{Measures}

A combination of survey and molecular genetic data were used in this analysis. Cigarette use initiation was measured using responses to the question, "During the past 3 months, about how many days did you smoke cigarettes?" The response categories were measured on a $0-5$ scale, representing "0 days," " 1 to 2 days," "3 to 5 days," "6 to 9 days," "10 to 19 days," and "20 days or more" respectively. Any cigarette use initiation is indicated by any valid response except " 0 days" when the respondent had not reported cigarette use in a previous wave; regular cigarette use is indicated by a response of " 6 to 9 days" or more when the respondent had not reported regular cigarette use in a previous wave. Respondents who reported that they had never had a puff of a cigarette or had not smoked in the past 3 months were assigned a value of 0 for both outcomes.

Neighborhood peer cigarette use is the key environmental indicator in this study. Although Daw and colleagues (Daw, et al., 2013) used school peer substance use as the key environmental measure, this was infeasible using the Genes in Context dataset because respondents were clustered in a small number of schools. However, because of the schoolbased sampling design of this study and the geographic basis of school assignment in the U.S., adolescent respondents were clustered together in census block groups $(\mathrm{N}=82)$. Accordingly, we measured peer cigarette use as the proportion of residents ${ }^{1}$ that reported ever smoking cigarettes in each block group in the first wave of data.

\footnotetext{
${ }^{1}$ We defined neighborhood of residence as the first observed neighborhood for this respondent, which was typically, but not always, from the first wave of data.
} 
Demographic controls were also measured using survey responses. Age and sex were measured straightforwardly by self-report. ${ }^{2}$ Racelethnicity was coded to differentiate whites, African Americans, Latinos, and members of other racial and ethnic groups. Parental education was measured in the adolescent questionnaire. Responses were recoded to differentiate persons who did not graduate from high school $(<\mathrm{HS})$, high school graduates (HS), those who attended some college (SC), college graduates (BA), and those with postbaccalaureate education $(>\mathrm{BA})$. The highest value reported throughout the period of the study is used for this measure.

These survey data were combined with molecular genetic data in this study. The 5HTTLPR polymorphism was assayed as described by Whisman and colleagues (Whisman, Richardson, \& Smolen, 2011). Briefly, the genotype calls were made using a modification (Anchordoquy, McGeary, Liu, Krauter, \& Smolen, 2003) of the PCR method described by Gelernter and colleagues (Gelernter, Cubells, Kidd, Pakstis, \& Kidd, 1999), yielding products of 376 or $419 \mathrm{bp}$ for the two most common short (14 repeat) and long (16 repeat) alleles (Nakamura, Ueno, Sano, \& Tanabe, 2000). Longer alleles with 18 to 22 repeats were found in 22 individuals and were combined with the 16 repeat alleles. The SNP rs25531, which allows determination of the $\mathrm{L}_{\mathrm{A}}$ and $\mathrm{L}_{\mathrm{G}}$ alleles, was assayed using the primer sequences described by $\mathrm{Hu}$ and colleagues (Hu, et al., 2005), then incubating the PCR products with 5 units of MspI (NEB, Ipswitch, MA) for 90 min at $37^{\circ} \mathrm{C}$ (Wendland et al, 2006). A 97 bp MspI restriction digest fragment indicates an $L_{G}$ allele. Lower-expressing $S$ and $\mathrm{L}_{\mathrm{G}}$ alleles were designated $\mathrm{S}^{\prime}$ and the higher-expressing $\mathrm{L}_{\mathrm{A}}$ allele was designated $\mathrm{L}$ '.

\section{Statistical Analysis}

We employed Cox proportional hazard models to account for the longitudinal nature of the data, predicting the initiation of different levels of smoking (rather than the levels themselves, as in Daw et al. 2013). We estimated all models using the stcox command in Stata 13, allowing for the non-independence of observations in neighborhoods using the clustered sandwich estimator. In this analysis, we estimated smoking initiation hazards (defined as any smoking or regular smoking) using two specifications. The first estimated smoking hazards as a function of neighborhood peer cigarette use and controls for age, race/ ethnicity, sex, and parental education. The second added the main and interactive effects of $5 H T T L P R$, specified additively as the number of $\mathrm{S}$ alleles. The gene-environment interaction effect of interest is between 5HTTLPR genotype and neighborhood peer cigarette use. In order to focus this analysis on smoking initiation, only person-wave combinations who did not report any or regular smoking in a previous wave were included in the model. Thus, all respondents are included from the first wave, whereas only respondents who did not report smoking in wave 1 are included in wave 2 , etc.

\footnotetext{
${ }^{2}$ In the genetic sub-sample, biological sex was also confirmed through amelogenin sex-typing.
} 


\section{RESULTS \\ Sample Composition}

Table 1 provides descriptive statistics on the sample. The sample is 50\% black and $41 \%$ white (with Hispanics and other groups comprising the remainder). About $8 \%$ of respondents' parents did not graduate high school, 25\% are high school graduates only, 29\% attended some college, $26 \%$ graduated college, and $12 \%$ have a parent with some postbaccalaureate schooling. The sample was about $49 \%$ female. The average respondent who ever reported cigarette usage in the past 30 days began in the $3^{\text {rd }}$ wave (mean wave $=3.19$, between $7^{\text {th }}$ and $9^{\text {th }}$ grade), and began regular cigarette use between $3^{\text {rd }}$ and $4^{\text {th }}$ wave (mean $=3.77,7^{\text {th }}-9^{\text {th }}$ grade). Both of these figures had a standard deviation of 2, though, so there was substantial variation in this characteristic. In the average neighborhood in the dataset, $42 \%$ of respondents reported having smoked at least once (even one puff), with a standard deviation of .09. Finally, this sample was approximately evenly divided on the counts of the $S^{\prime}$ and L' alleles for $5 H T T L P R$, as $50 \%$ of the sample is heterozygous and about $25 \%$ is homozygous for S' and L' each.

\section{Neighborhood Peer Effects on Cigarette Use Initiation}

Table 2 shows the results of all regression analyses, which are also graphically illustrated in Figures 2 and 3. First, the results show that, net of demographic controls, neighborhood peer cigarette use is a significant predictor of any cigarette use initiation in this sample, with a hazard ratio of 3.6 ( $\mathrm{p} \unlhd$ (001). This analysis only included person-wave observations in which the person had not previously reported cigarette use prior to the wave in question. Similar effects were observed for regular smoking initiation, which yields a hazard ratio of $3.9(\mathrm{p} \unlhd .001)$.

Figure 2 depicts how the hazard of initiating cigarette use declined over time for all groups, but is well-ordered by neighborhood cigarette use. Those in the $90^{\text {th }}$ percentile of neighborhood peer use have a hazard of initiation about .025 higher than the $10^{\text {th }}$ percentile at the beginning of the observed time interval and about .015 higher at the end. The hazards of regular smoking initiation are lower in all time periods observed, but are also wellordered by neighborhood peer cigarette use.

\section{Gene-Environment Interaction in Cigarette Use Initiation}

Table 2 also shows the results of gene-environment interaction models of cigarette use initiation. In both the any and regular use models, there is no statistically significant main effect of neighborhood peer cigarette use. Instead, a gene-environment interaction is observed in the expected direction, such that those with more copies of the $5 H T T L P R^{*} \mathrm{~S}$ ' allele show statistically significantly higher hazards of smoking initiation in environments where a higher proportion of their neighborhood peers smoked in the first wave. These hazard ratios were large: 3.5 ( $\mathrm{p}=0.002$ ) for any smoking, and 5.6 ( $\mathrm{p} \unlhd$ ).001) for regular smoking. These effects were observed alongside controls for sex, race/ethnicity, grade in the first wave, and parental education. 
Figure 3 shows that, for any cigarette use, the effect is immediately clear: persons in highsmoking neighborhoods with two copies of the $5 H T T L P R *$ S' allele show substantially elevated hazards of smoking initiation compared to persons in low-smoking neighborhoods and/or persons with no copies of the $5 H T T L P R^{*} \mathrm{~S}$ ' allele. These results are consistent with the diathesis-stress model. The effect on regular cigarette use is equally stark: the hazard of regular smoking initiation for those in the $90^{\text {th }}$ percentile of neighborhood peer smoking is actually reduced compared to the $10^{\text {th }}$ percentile among those with no copies of the $5 H T T L P R * \mathrm{~S}$ ' allele; in contrast, the hazard of regular smoking initiation is substantially elevated for persons in high smoking neighborhoods for those with two copies of the $5 H T T L P R^{*} \mathrm{~S}$ ' allele. These results are consistent with the differential susceptibility model.

\section{DISCUSSION AND CONCLUSION}

In this paper, we provide evidence that supports previous findings on the interactive effects of peer smoking, 5HTTLPR, and individual smoking (Daw, et al., 2013). Specifically, the neighborhood proportion of cigarette users shows statistical interactions with the 5HTTLPR locus to predict an individual's hazard of any and regular smoking initiation. We find support for both the diathesis-stress (for any smoking) and differential susceptibility (for regular smoking) gene-environment interaction models. These findings are similar to those found in the Daw and colleagues study (Daw, et al., 2013), despite differences in the peer behaviors observed (neighborhood peers vs. schools) and form of the dependent variable (hazards of smoking initiation rather than level of smoking reported). This study therefore provides additional evidence that the smoking behavior of adolescents is related to that of their peers interactively by $5 H T T L P R$.

Our findings are important because they continue to broaden the environmental lens to focus on social factors within meso-level contexts as important determinants of genetic associations. They suggest that peer behaviors predict individual behavior, but that the strength of these effects are genetically contingent. Although the prevalence of behaviors are not strictly equivalent to social norms, this interpretation is consistent with previous research showing that smoking behavioral norms have measurable influences on the gene-smoking relationship (Boardman, et al., 2008). For example, Boardman, Blalock, \& Pampel (2010) estimated the heritability of smoking across nearly 40 years and show that its lowest level was in 1964. After the release of the Surgeon General's Report in that same year, however, the heritability of smoking onset increased significantly over time. They conclude that those least genetically disposed toward smoking were more likely to avoid smoking initiation once they had knowledge of the health risks of smoking. Similarly, if neighborhoods were smoking is more common are also those where smoking is considered more permissible, the present findings may reflect a similar influence of social norms on individual behavior. However, in this case the current finding suggests that individual susceptibility to these normative influences is structured by $5 H T T L P R$ genotype.

Additionally, differentiating between diathesis-stress and differential susceptibility models may provide clues about the mechanisms underlying the relationship between peer and individual behavior. For example, those with an increasing number of short alleles are not more likely to avoid smoking any cigarettes if they reside in the healthiest neighborhoods, 
contrary to the predictions of the differential susceptibility hypothesis. Instead, it is much more in line with the diathesis-stress model. Therefore, because stress is the hypothesized mechanism underlying diathesis-stress theory, it is possible that this measure of peer cigarette smoking behavior is also correlated with the average level of stress exposure in the neighborhood, and that the 5HTTLPR conclusion by Caspi et al. (Caspi, et al., 2002) therefore best explains this pattern. This is plausible because cigarette use is a well-known behavior to cope with chronic stress exposure among adults (Jackson, Knight, \& Rafferty, 2010), and smokers experience an immediate reduction in perceived stress after smoking (Cohen \& Lichtenstein, 1990). As such, we encourage future researchers to examine the social influences that we describe while including detailed information about the stress exposure levels across neighborhoods. Similarly, as described earlier, a large body of work has detailed the physiological pathways through which the $\mathrm{S}$ allele affects transcriptional activity and lower serotonin uptake but the direct link to smoking behaviors is quite mixed (Gerra et al. 2005; Ishikawa et al. 1999; Trummer et al. 2006; and Kremer et al. 2005). Some of this inconsistency could be due to specific characteristics of study designs that have not considered the broad social environment as a fundamental precursor to some of the biological mechanisms related to substance use in general (Boardman, Daw, and Freese 2013). Together with more detailed genetic markers future research can build on our work by examining specific biological pathways through which complex social factors differentially influence complex health behaviors differently for individuals with different genetic composition.

The fact that our results for regular smoking conform to the differential susceptibility model is also important because it indicates that these sensitivity alleles may be particularly sensitive to social environmental cues about smoking regularity. Regular smoking constitutes a lifestyle influenced by shared meanings (Frohlich, Corin, \& Potvin, 2002), whereas any smoking may merely be an isolated action. Therefore, the heightened response to environmental cues about smoking among carriers of the short allele suggests that the concept of environmental sensitivity should be extended to include normative forces to which individuals are exposed. These results suggest that the norm of the neighborhood structures if an individual smokes but also how frequently they smoke, and that S'/S' carriers are more influenced by both processes.

There are a number of key limitations to this study. First, we did not directly control for population stratification. However, we believe it is unlikely that these results are biased because there were no statistically significant differences in allele frequency by race/ ethnicity in this sample. Although race is not equivalent to ancestry, others have indicated that self-reported race captures a large portion of genetic differences that exist across racial and ethnic groups (Sucheston, et al., 2012). Second, this dataset is not population representative, and is instead drawn from a sample of a small number of schools in a geographically restricted area. However, the original Daw and colleagues investigation (Daw, et al., 2013) used population representative data and obtained similar findings, suggesting that these results are not unique to this subpopulation. Additionally, the biospecimen response rate in this study was only $40 \%$, raising the possibility that selection processes may bias these results. However, the direct refusal rate was only $13 \%$, somewhat 
lessening this concern. Finally, given the important role that stress plays in smoking behavior and the degree to which stressors cluster in neighborhoods, we cannot eliminate the possibility that these relationships may be explained by neighborhood stress, not peer behaviors. However, if this were the case, this would nonetheless represent a geneenvironment interaction, only with a different environmental characteristic.

\section{Acknowledgments}

Role of funding sources: This research was supported by NIH grants R24 HD066613 and T32 HD007289. Data collection for the study was supported by NICHD grant R01 HD057222, NIDA grant R01 DA13459, and CDC Grant R49 CCV423114. These funding agencies played no role in the design of this study.

\section{References}

Alexander C, Piazza M, Mekos D, Valente T. Peers, schools, and adolescent cigarette smoking. Journal of Adolescent Health. 2001; 29:22-30. [PubMed: 11429302]

Anchordoquy HC, McGeary C, Liu L, Krauter KS, Smolen A. Genotyping of three candidate genes following whole genome preamplification of DNA collected from buccal cells. Behavior Genetics. 2003; 33:73-78. [PubMed: 12645824]

Belsky J, Pluess M. Beyond diathesis stress: Differential susceptibility to environmental influences. Psychological Bulletin. 2009; 135:885-908. [PubMed: 19883141]

Boardman JD, Barnes LL, Wilson RS, Evans DA, de Leon CFM. Social disorder, APOE-e4 genotype, and change in cognitive function among older adults living in chicago. Social Science \& Medicine. 2012; 74:1584-1590. [PubMed: 22465377]

Boardman JD, Blalock CL, Pampel FC. Trends in the genetic influences on smoking. Journal of Health and Social Behavior. 2010; 51:108-123. [PubMed: 20420298]

Boardman JD, Saint Onge JM, Haberstick BC, Timberlake DS, Hewitt JK. Do schools moderate the genetic determinants of smoking? Behavior Genetics. 2008; 38:234-246. [PubMed: 18347970]

Breslau N, Fenn N, Peterson EL. Early smoking initiation and nicotine dependence in a cohort of young-adults. Drug and Alcohol Dependence. 1993; 33:129-137. [PubMed: 8261877]

Caspi A, McClay J, Moffitt TE, Mill J, Martin J, Craig IW, Taylor A, Poulton R. Role of genotype in the cycle of violence in maltreated children. Science. 2002; 297:851-854. [PubMed: 12161658]

Caspi A, Sugden K, Moffitt TE, Taylor A, Craig IW, Harrington H, McClay J, Mill J, Martin J, Braithwaite A, Poulton R. Influence of life stress on depression: Moderation by a polymorphism in the 5-htt gene. Science. 2003; 301:386-389. [PubMed: 12869766]

Chahine T, Subramanian SV, Levy JI. Sociodemographic and geographic variability in smoking in the us: A multilevel analysis of the 2006-2007 current population survey, tobacco use supplement. Social Science \& Medicine. 2011; 73:752-758. [PubMed: 21813218]

Chassin L, Presson CC, Sherman SJ, Corty E, Olshavsky RW. Predicting the onset of cigarettesmoking in adolescents - a longitudinal study. Journal of Applied Social Psychology. 1984; $14: 224-243$.

Cicchetti D. Resilience under conditions of extreme stress: A multilevel perspective. World Psychiatry. 2010; 9:145-154. [PubMed: 20975856]

Cohen S, Lichtenstein E. Perceived stress, quitting smoking, and smoking relapse. Health Psychology. 1990; 9:466-478. [PubMed: 2373070]

Conley D, Rauscher E, Siegal ML. Beyond orchids and dandelions: Testing the 5-htt "risky" allele for evidence of phenotypic capacitance and frequency-dependent selection. Biodemography and Social Biology. 2013; 59:37-56. [PubMed: 23701535]

Daw J, Shanahan M, Harris KM, Smolen A, Haberstick B, Boardman JD. Genetic sensitivity to peer behaviors, 5HTTLPR, smoking, and alcohol consumption. Journal of Health and Social Behavior. 2013; 54:92-108. [PubMed: 23292504]

Department of Health and Human Services, U. S.. Preventing tobacco use among youth and young adults: A report of the surgeon general. In: CDC, U.S. Department of Health and Human Services, 
National Center for Chronic Disease Prevention and Health Promotion, Office on Smoking and Health. , editor. Atlanta, GA: 2012.

Duncan C, Jones K, Moon G. Smoking and deprivation: Are there neighbourhood effects? Social Science \& Medicine. 1999; 48:497-505. [PubMed: 10075175]

Ehringer MA, McQueen MB, Hoft NR, Saccone NL, Stitzel JA, Wang JC, Bierut LJ. Association of CHRN genes with "dizziness" to tobacco. American Journal of Medical Genetics Part BNeuropsychiatric Genetics. 2010; 153 B:600-609.

Eitle DJ, Eitle TM. School and county characteristics as predictors of school rates of drug, alcohol, and tobacco offenses. Journal of Health and Social Behavior. 2004; 45:408-421. [PubMed: 15869113]

Ellis BJ, Boyce WT, Belsky J, Bakermans-Kranenburg MJ, van Ijzendoorn MH. Differential susceptibility to the environment: An evolutionary-neurodevelopmental theory. Development and Psychopathology. 2011; 23:7-28. [PubMed: 21262036]

Frohlich KL, Corin E, Potvin L. A theoretical proposal for the relationship between context and disease. Sociology of Health \& Illness. 2002; 23:776-797.

Frohlich KL, Potvin L, Gauvin L, Chabot P. Youth smoking initiation: Disentangling context from composition. Health \& Place. 2002; 8:155-166. [PubMed: 12135639]

Gelernter J, Cubells JF, Kidd JR, Pakstis AJ, Kidd KK. Population studies of polymorphisms of the serotonin transporter protein gene. American Journal of Medical Genetics. 1999; 88:61-66. [PubMed: 10050969]

Gerra G, Garofano L, Zaimovic A, Moi G, Branchi B, Bussandri M, Brambilla F, Donnini C. Association of the serotonin transporter promoter polymorphism with smoking behavior among adolescents. Am J Med Genet B Neuropsychiatr Genet. 2005; 135B:73-78. [PubMed: 15806583]

Hu X, Oroszi G, Chun J, Smith TL, Goldman D, Schuckit MA. An expanded evaluation of the relationship of four alleles to the level of response to alcohol and the alcoholism risk. Alcoholism: Clinical and Experimental Research. 2005; 29:8-16.

Ishikawa H, Ohtsuki T, Ishiguro H, Yamakawa-Kobayashi K, Endo K, Lin YL, Yanagi H, Tsuchiya S, Kawata K, Hamaguchi H, Arinami T. Association between serotonin transporter gene polymorphism and smoking among japanese males. Cancer Epidemiol Biomarkers Prev. 1999; 8:831-833. [PubMed: 10498403]

Jackson JS, Knight KM, Rafferty JA. Race and unhealthy behaviors: Chronic stress, the hpa axis, and physical and mental health disparities over the life course. American Journal of Public Health. 2010; 100:933-939. [PubMed: 19846689]

Kremer I, Bachner-Melman R, Reshef A, Broude L, Nemanov L, Gritsenko I, Heresco-Levy U, Elizur Y, Ebstein RP. Association of the serotonin transporter gene with smoking behavior. Am J Psychiatry. 2005; 162:924-930. [PubMed: 15863794]

Monroe SM, Simons AD. Diathesis stress theories in the context of life stress research - implications for the depressive-disorders. Psychological Bulletin. 1991; 110:406-425. [PubMed: 1758917]

Nakamura M, Ueno S, Sano A, Tanabe H. The human serotonin transporter gene linked polymorphism (5-httlpr) shows ten novel allelic variants. Mol. Psychiatry. 2000; 5:32-38. [PubMed: 10673766]

Pedneault M, Labbe A, Roy-Gagnon MH, Low NC, Dugas E, Engert JC, O'Loughlin J. The association between chrn genetic variants and dizziness at first inhalation of cigarette smoke. Addictive Behaviors. 2014; 39:316-320. [PubMed: 24119711]

Saccone NL, Saccone SF, Hinrichs AL, Stitzel JA, Duan WM, Pergadia ML, Agrawal A, Breslau N, Grucza RA, Hatsukami D, Johnson EO, Madden PAF, Swan GE, Wang JC, Goate AM, Rice JP, Bierut LJ. Multiple distinct risk loci for nicotine dependence identified by dense coverage of the complete family of nicotinic receptor subunit (CHRN) genes. American Journal of Medical Genetics Part B-Neuropsychiatric Genetics. 2009; 150B:453-466.

Simons RL, Lei MK, Beach SRH, Brody GH, Philibert RA, Gibbons FX. Social environment, genes, and aggression: Evidence supporting the differential susceptibility perspective. American Sociological Review. 2011; 76:883-912.

Sucheston LE, Bensen JT, Xu ZL, Singh PK, Preus L, Mohler JL, Su LJ, Fontham ETH, Ruiz B, Smith GJ, Taylor JA. Genetic ancestry, self-reported race and ethnicity in african americans and european americans in the pcap cohort. Plos One. 2012; 7 
Trummer O, Koppel H, Wascher TC, Grunbacher G, Gutjahr M, Stanger O, Ramschak-Schwarzer S, Boehm BO, Winkelmann BR, Marz W, Renner W. The serotonin transporter gene polymorphism is not associated with smoking behavior. Pharmacogenomics J. 2006; 6:397-400. [PubMed: 16702982]

Whisman MA, Richardson ED, Smolen A. Behavioral inhibition and triallelic genotyping of the serotonin transporter promoter (5-httlpr) polymorphism. Journal of Research in Personality. 2011; 45:706-709.

World Health Organization. Tobacco. Fact Sheet. 2012; 339 


\section{Highlights}

P Prior research shows GxEs between school smoking, 5HTTLPR, and individual smoking

This paper extends this finding to neighborhood peers in independent sample

Results support both diathesis-stress and differential susceptibility models 
a.

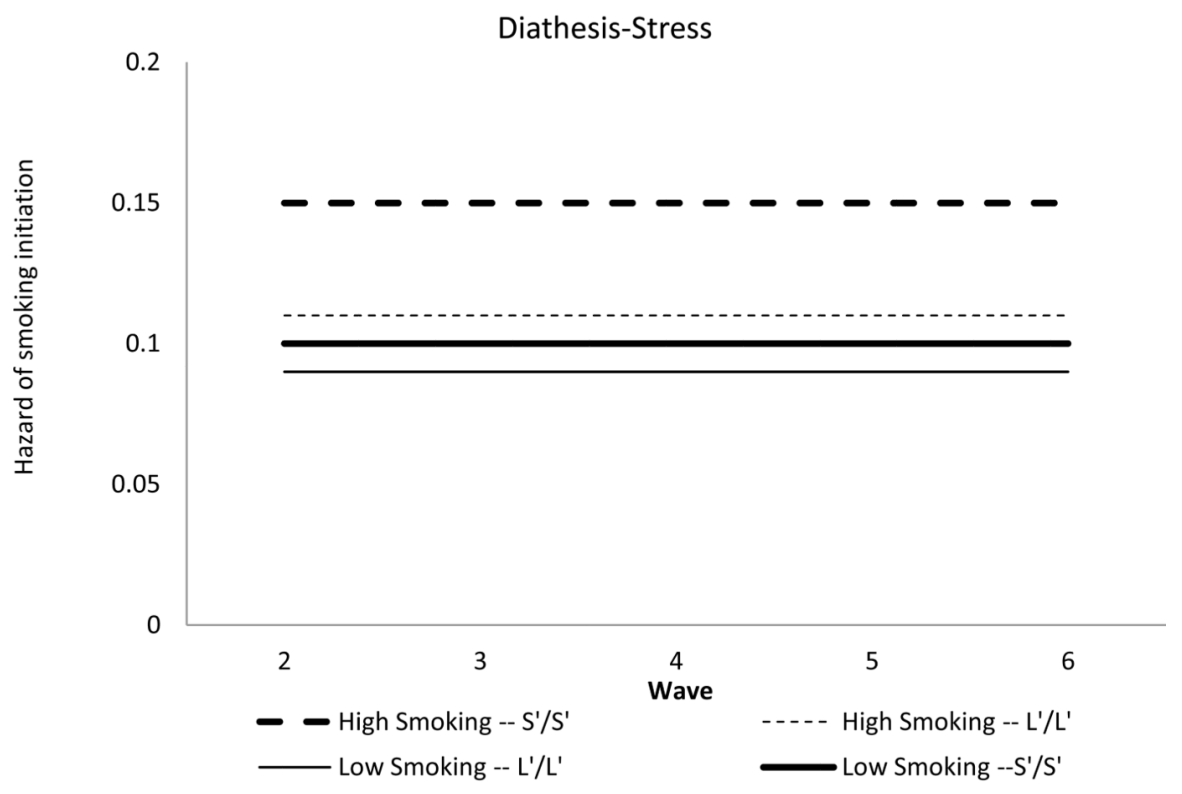

b.

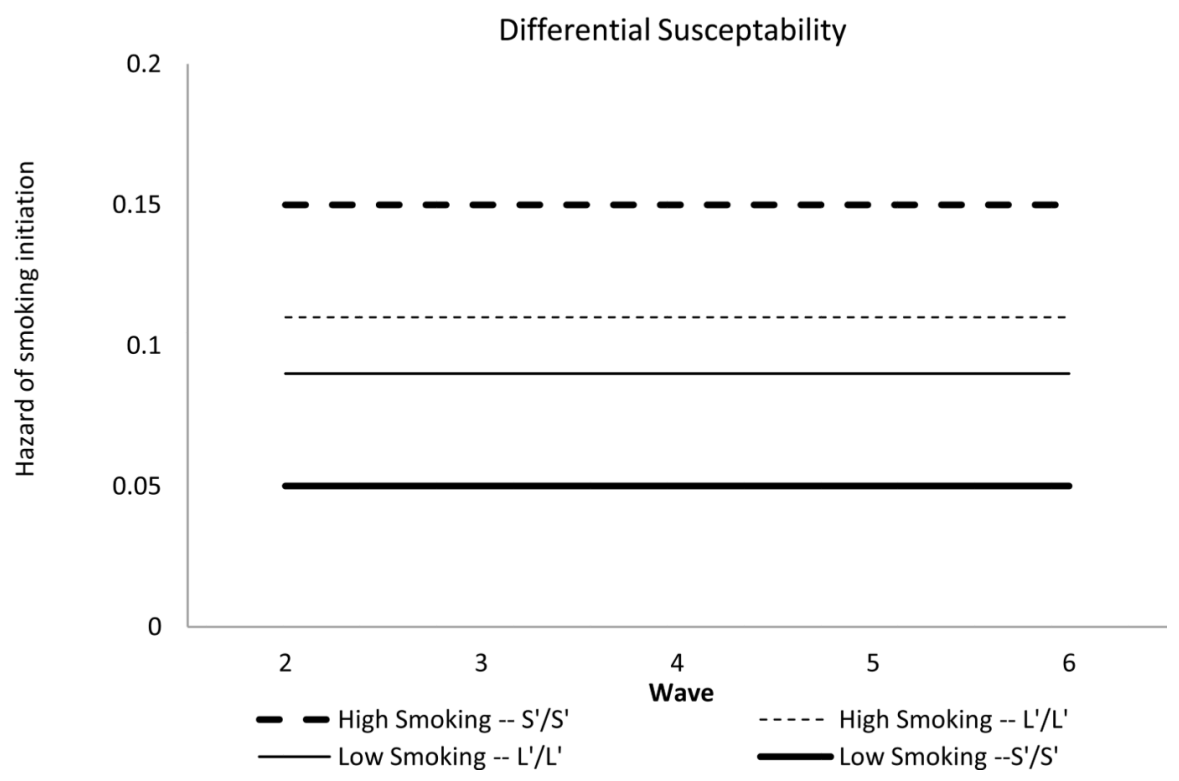

Figure 1.

a. Diathesis-Stress GxE Model for Smoking Initiation as a Function of Neighborhood Level Smoking and Genotype.

b. Differential Susceptibility GxE Model for Smoking Initiation as a Function of Neighborhood Level Smoking and Genotype. 


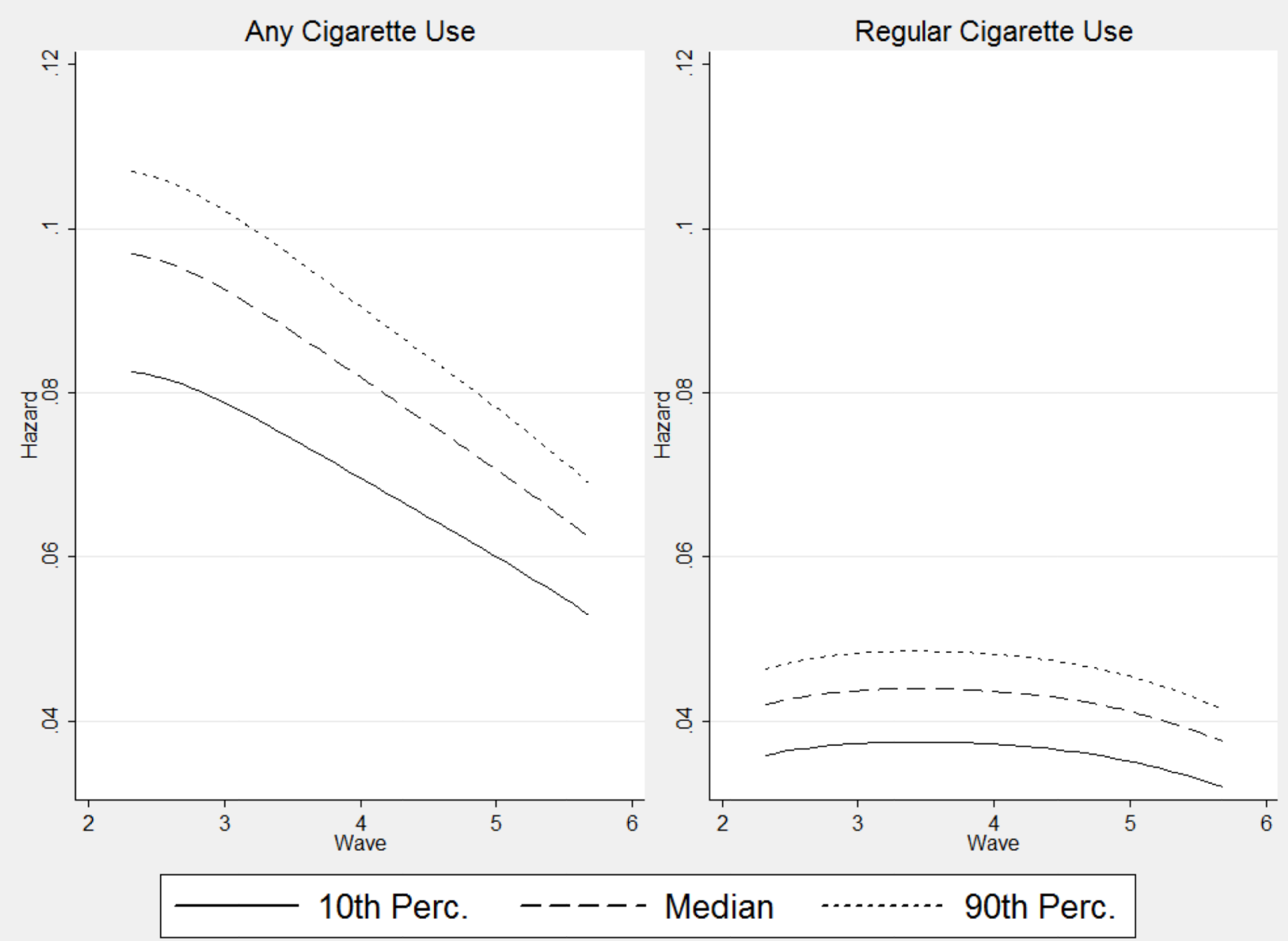

Figure 2.

Estimated Hazards of Any and Regular Cigarette Smoking Initiation, by Neighborhood Cigarette Smoking Mean 


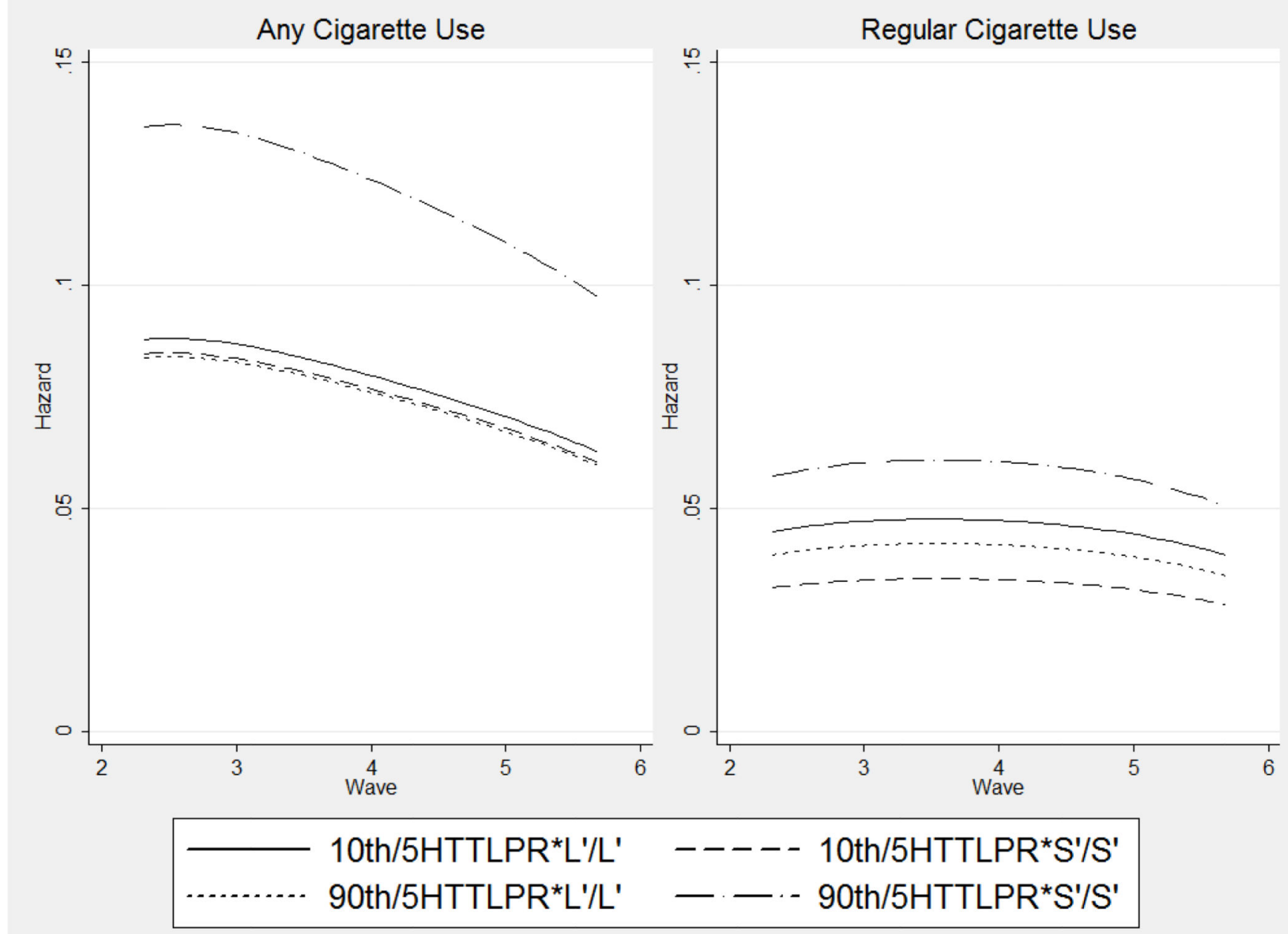

Figure 3.

Estimated Hazards of Any or Regular Cigarette Smoking Initiation, by Neighborhood Cigarette Smoking Mean and 5HTTLPR

NOTE: All 5HTTLPR genotypes were modeled additively. Only the L'/L' and S'/S' genotypes are shown for visual clarity. 


\section{Table 1}

\section{Descriptive Statistics}

\begin{tabular}{|llll|}
\hline Variable & N & Mean/\% & SD \\
\hline Wave 1st Cig. & 1,846 & 3.19 & 1.99 \\
Wave 1st Reg. Cig. & 1,090 & 3.77 & 1.97 \\
NH Cig. Mean & 3,839 & 0.42 & 0.09 \\
5HTTLPR ${ }^{*}$ ' & 1,432 & & \\
0 & & 24.72 & -- \\
1 & & 49.86 & -- \\
2 & & 25.42 & -- \\
Sex & 3,757 & & \\
Male & & 50.84 & -- \\
Female & & 49.16 & -- \\
Race & 3,756 & & \\
White & & 40.68 & -- \\
Black & & 50.27 & -- \\
Hispanic & & 3.38 & -- \\
Other & & 5.67 & -- \\
Parental Education & 3,615 & & \\
<HS & & 7.63 & -- \\
HS & & 24.95 & -- \\
SC & & 28.55 & -- \\
BA & & 26.47 & -- \\
>BA & & 12.39 & -- \\
\hline
\end{tabular}

NOTE: Wave $1^{\text {st }}$ cigarette and grade $1^{\text {st }}$ regular cigarette smoking descriptive statistics were calculated only among respondents that ever reported cigarette smoking. The parental education categories may be interpreted as follows: " $<\mathrm{HS}$ " indicates they did not complete high school; "HS" indicates a high school diploma or equivalent; "SC" indicates they attended post-secondary school but did not complete a four-year degree; "BA" indicates they received a four-year degree; “>BA" indicates they attended or completed graduate-level degree programs. 


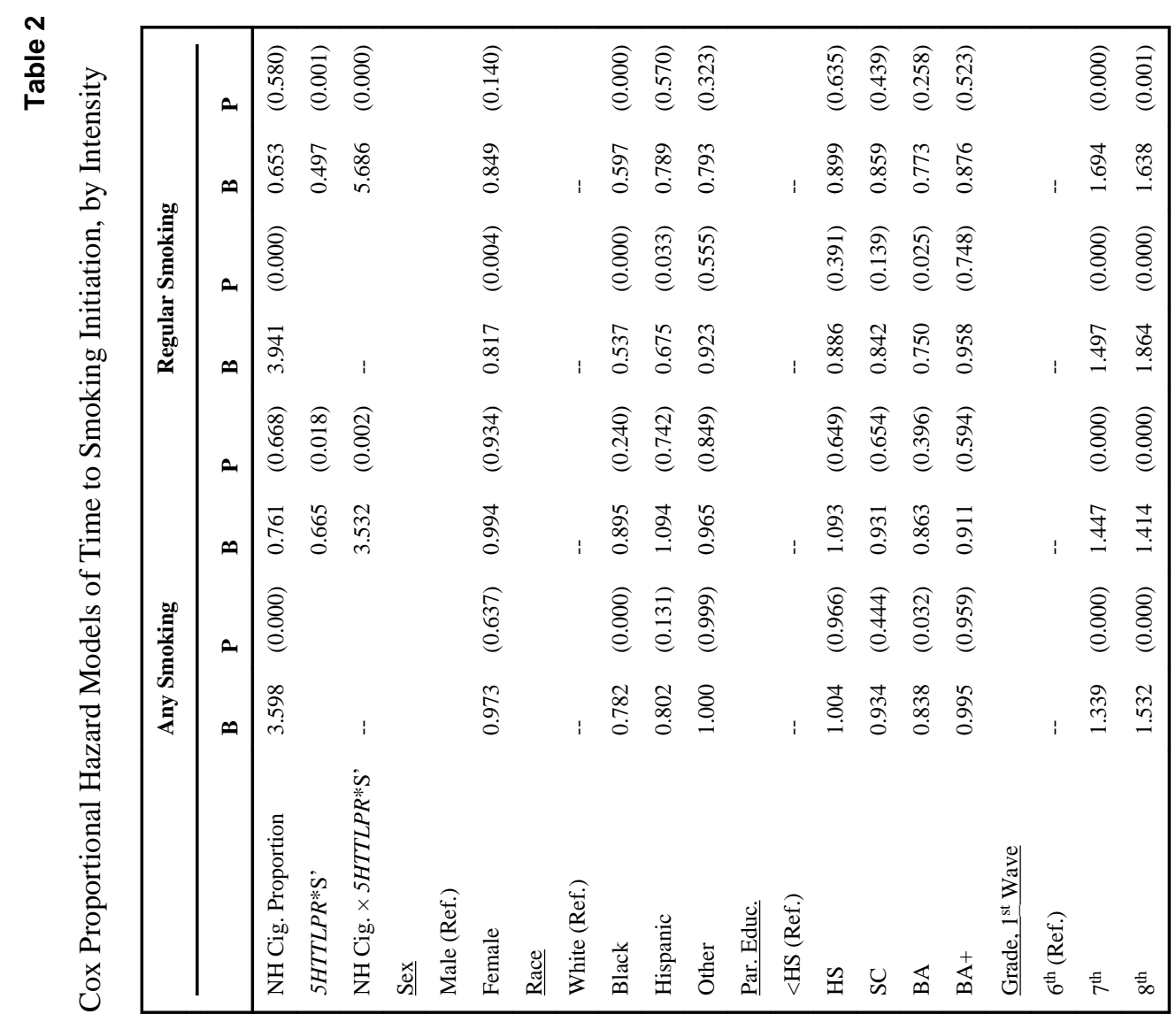

